\title{
The relationship between memory performance and the number of rehearsals in free recall
}

\author{
HIROYUKI SHIMIZU \\ Osaka City University, Osaka, Japan
}

\begin{abstract}
The purpose of the present study was to examine the relationship between the number of rehearsals and long-term recall performance by means of an overt rehearsal procedure. Subjects were induced to concentrate their rehearsal activity on specific items in free recall tasks. In Experiment 1 , both the primacy and the recency items that had received additional rehearsals were recalled with higher probability than were the ordinarily rehearsed items in immediate recall but not in final recall. Experiment 2 was designed to extend the occasions for subjects' rehearsal by manipulating the rate of item presentation. The overall pattern of resulting data showed that for neither recency items nor primacy items does the additional overt rehearsal reliably lead to facilitative effects on long-term recall performance. The possibility of a qualitative change in rehearsal is discussed.
\end{abstract}

The multistore model of human memory, which postulates that there are several memory-storage systems, such as short-term and long-term stores, is based mainly on analyses of serial position curves resulting from free recall tasks (Atkinson \& Shiffrin, 1968, 1971). A U-shaped serial position curve in immediate free recall is consistently obtained, and according to this model, the high recall probability of the first few items (primacy effect) and of the last few items (recency effect) reflects output from the long-term and short-term stores, respectively. Presumably, the nearer to the beginning of a list an item is, the more frequently it will be rehearsed. It has been suggested that this can account for the so-called primacy effect, since in this model it is assumed that the probability of information transfer to long-term storage increases with rehearsal frequency of an item.

This possibility was supported by experimental data from Rundus and Atkinson (1970) and Rundus (1971), who examined the relationship between free recall performance and the number of rehearsals by means of an overt rehearsal procedure. The subjects were instructed to study a word list by repeating items aloud during presentation, and their overt rehearsals were taperecorded. The resulting free recall performance showed a typical U-shaped curve, in which the mean number of rehearsals was highest for the beginning items and gradually decreased with items' serial positions. Hence, for prerecency items the number of rehearsals correlated highly with the probability of recall.

Further support for the role of rehearsal in long-term storage came from Craik (1970), who gave an unexpected

\footnotetext{
The author is greatly indebted to Associate Professor Ryozo Yukawa of Osaka City University for his advice and guidance. Requests for reprints should be sent to Hiroyuki Shimizu at Department of Psychology, Faculty of Letters, Osaka City University, Sumiyoshi-ku, Osaka 558, Japan.
}

final free recall test on all items from a previous series of immediately recalled lists. In contrast with the immediate recall tests, in final recall, recency items were found to be recalled most poorly (subsequently dubbed the negative recency effect). If final recall performance is considered to be reflective of output from the long-term store, but not from the short-term store, the negative recency effect is to be expected, since the last few items tend to receive the fewest overt rehearsals.

An alternative view on the role of rehearsal in memory processes was provided by Craik and Watkins (1973). In their Experiment 2, the subjects were presented 12 12word lists that they were required to rehearse aloud. The last 4 words in each list were printed in capital letters, and the subjects were instructed to memorize those 4 items intensively. The initial recall was required immediately for half of the 12 lists, and for the other half, recall was required after an unfilled delay of $20 \mathrm{sec}$, during which subjects were free to continue to rehearse overtly. At the end of the last initial recall, an unexpected test of final free recall was given. The results of this experiment showed that even though the last four items received more rehearsals in the delayed condition than in the immediate condition, the probability of final free recall was essentially the same, with both sets of results indicating a negative recency effect. Therefore, on the basis of these results, Craik and Watkins claimed that a negative recency effect cannot be attributed to a deficiency in the amount of rehearsal. They argued that for prerecency items, elaborative rehearsal, which facilitates long-term recall, had been executed, whereas for recency items, maintenance rehearsal, which maintains information in the short-term store, had been exercised. This dichotomy of rehearsal types stems from the levels-of-processing theory of Craik and Lockhart (1972).

The purpose of the present study was to further explore which aspect of rehearsal, quantitative or qualitative, 
should be emphasized with regard to free recall list learning. Although Craik and Watkins (1973) found that for recency items long-term performance is not regulated by the number of rehearsals, it still remains unclear whether the amount of rehearsal for prerecency items has an effect on their long-term recall. If rehearsal is a principal component of long-term retention, there should be a correspondence between the number of rehearsals and recall of prerecency items, to the extent that they undergo more rehearsal.

\section{EXPERIMENT 1}

Experiment 1 was designed to examine the relationship between the number of rehearsals and long-term recall performance for both recency and primacy items.

\section{Method}

Design and Subjects. The experimental design was a $3 \times 3$ factorial. The first factor corresponded to an experimental manipulation to focus subjects' rehearsal activity. It was composed of a control group (C) and two experimental groups, one of which was induced to rehearse primacy items (PR) and the other to rehearse recency items (RR) as many times as possible. The second factor was the serial position of recalled list items, that is, primacy, middle, or recency.

Fifty-four undergraduates at Osaka City University participated in this experiment. They were randomly assigned to the three rehearsal-manipulation groups of 18 subjects.

Materials and Apparatus. Seventy-two common words were randomly chosen, ranging in familiarity values from 3.00 to 3.49 of Japanese three-letter nouns written in katakana (Koyanagi, Ishikawa, Ohkubo, \& Ishii, 1960). These words were divided into six lists of 12 items. The items within a list were unrelated to each other semantically and phonologically. The experiment was controlled via an NEC Personal Computer, Model PC-8001. All the items were presented visually on a color display (PC-8049N).

Procedure. The subjects were tested individually. They were instructed that they should study the words appearing on the display while rehearsing overtly. After the list presentation was over, they were to write down as many items as possible without regard to the order of presentation.

For the PR group, the first four items within each list were presented in red letters and the remaining items in white. For the RR group, the last four items were in red and the rest were in white. For the $\mathbf{C}$ group, all the list items were in white. Both PR and RR groups were told that the items in red letters were particularly important and should be memorized well.

All the items were presented at a 4-sec rate. Before the presentation of each list, a 2-sec warning signal was displayed, and the last item was followed by a 2 -sec ending signal. Immediately after the ending signal, $1 \mathrm{~min}$ was allowed for subjects to recall the list items. The presentation order of lists was counterbalanced across subjects.

After all six lists had been presented, there was a $30-\sec$ backward counting task to eliminate the recency effect; subjects counted backward by 3s from 1,000 as fast as possible. Subjects were then given an unexpected test of final free recall, for which 3 min were allowed.

Prior to the six lists, all subjects were given a practice list. Data from it were not analyzed. Overt rehearsal activities of each subject were tape-recorded. Two subjects were found to have expected the final memory test by a postexperimental interview, so they were replaced.

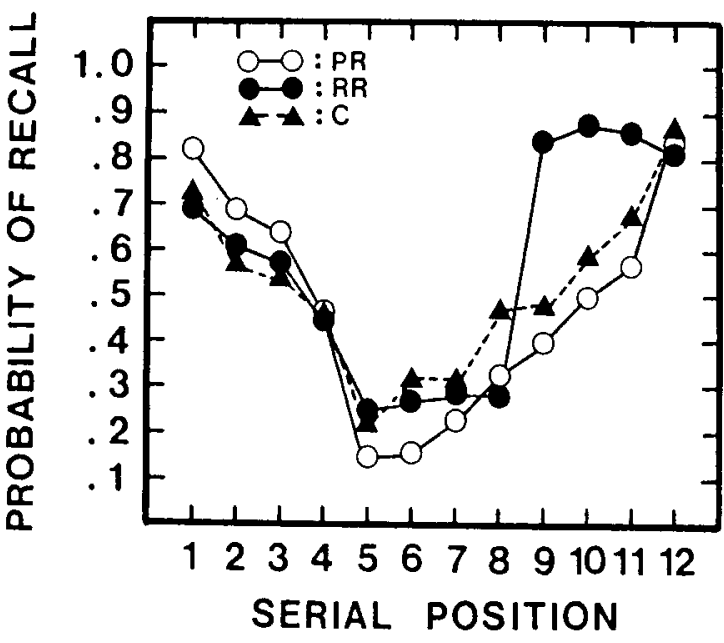

Figure 1. Serial position curves of immediate free recall for control (C), primacy rehearse (PR), and recency rehearse (RR) groups (Experiment 1).

\section{Results and Discussion}

Immediate free recall. The performance on immediate free recall for the $C, P R$, and $R R$ groups is shown in Figure 1. A 3 (rehearsal manipulation) $\times 3$ (serial position) analysis of variance indicated that both main effects were significant [for group, $F(2,51)=5.48$, $p<.01$; for serial position, $F(2,102)=165.54$, $p<.001]$. Their interaction was also significant $[F(4,102)=11.07, p<.001]$. Compared with the C group, the PR group tended to be superior in memory for words in the primacy positions $[F(1,102)=3.58, .10$ $>p>.05]$ but inferior in memory for those in the middle and recency positions $[F(1,102)=6.28, p<.05$; $F(1,102)=3.38, .10>p>.05]$. On the other hand, performance of the RR group was roughly equivalent to that of the $\mathrm{C}$ group in memory for the primacy and middle positions of the lists, but was much better in memory for the recency positions $[F(1,102)=19.25, p<.001]$.

Final free recall. The performance on final free recall is shown in Figure 2. No difference among the three

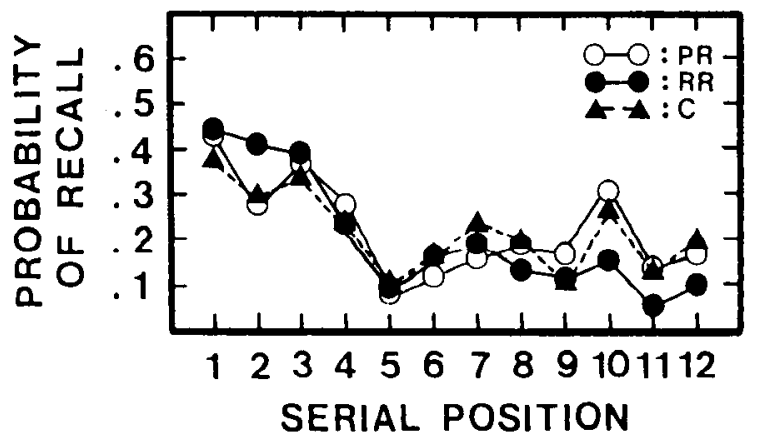

Figure 2. Serial position curves of final free recall for control (C), primacy rehearse (PR), and recency rehearse (RR) groups (Experiment 1). 
groups was detected $(F<1)$, and only the main effect of serial position was significant $[F(2,102)=57.92$, $p<.001]$. Across the three groups, the probability of recall from the middle positions was not different from that of the recency positions, so no evidence of a negative recency effect was found.

The mean number of rehearsals. The mean number of rehearsals that each list item received during list presentation is shown in Figure 3. The main effect of serial position was significant $[F(2,102)=156.82, p<.001]$, as was the interaction between the two factors $[F(4,102)=13.96, p<.001]$. As compared with the $C$ group, the PR group had a higher rehearsal probability for primacy items $[F(1,102)=13.34, p<.001]$, but there was no difference for items in the middle and recency positions (both $F \mathrm{~s}<1$ ). Similarly, the RR group's performance was nearly equivalent to that of the $\mathrm{C}$ group in the primacy and middle regions (both $F_{\mathrm{s}}<1$ ), but was extremely superior to that of the $\mathrm{C}$ group in the recency region $[F(1,102)=22.75, p<.001]$. Rehearsal frequency of the RR group increased abruptly at the ninth serial position and then gradually decreased.

From these results, the relationship between serial position effects and the number of rehearsals can be explicated as follows. The $\mathrm{C}$ group performed the free recall task in the usual fashion. As in previous studies (Craik, 1970; Rundus \& Atkinson, 1970), primacy and recency effects were obtained at the time of immediate recall, but there was no difference between recall of words in the middle and those in the recency regions in final recall; thus the negative recency effect was not obtained. Furthermore, the function relating the number of rehearsals to serial position had a resemblance to the serial position curve in final recall. Therefore, the results of the $\mathrm{C}$ group do not contradict the idea that long-term recall can be attributable to the amount of rehearsal.

The RR group rehearsed recency items more frequently and recalled them in the immediate recall test with higher

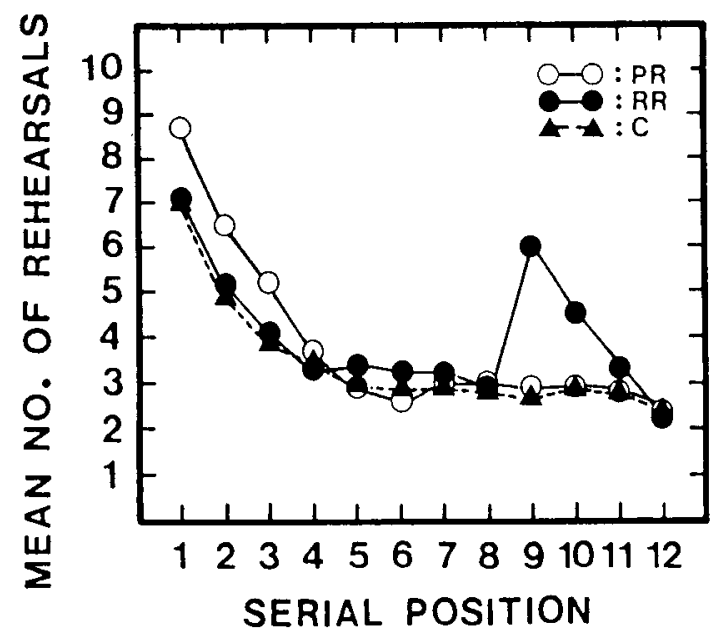

Figure 3. Mean number of overt rehearsals as a function of serial position (Experiment 1). probability than did the $\mathbf{C}$ group. There was no difference, however, between performances by the RR and $\mathrm{C}$ groups in final recall. This was consistent with Craik and Watkins's (1973) finding that the increase in the number of rehearsals for recency items is not related to longterm recall.

The PR group rehearsed primacy items more frequently and recalled them in the immediate recall test with slightly higher probability than did the $\mathrm{C}$ group, but in final recall no difference between the PR and $C$ groups was found. This result suggests that even for primacy items, the increase in the number of rehearsals was not related to longterm recall. However, the number of rehearsals by the PR group for primacy items increased only by two at most as compared with rehearsals by the $\mathrm{C}$ group. Since the immediate recall performance of the PR group for primacy items was not significantly superior to that of the $C$ group, it is possible that there was not sufficient time for subjects to rehearse enough to facilitate final recall performance. Therefore, Experiment 2 provided additional rehearsal time by manipulating the rate of item presentation.

\section{EXPERIMENT 2}

Experiment 2 was designed to examine further the relationship between the number of rehearsals and long-term recall performance for primacy items. It was meant to test the hypothesis that the PR group would show superior recall to that of the $\mathrm{C}$ group in the primacy region, if time sufficient to rehearse the items was allowed.

\section{Method}

Design and Subjects. The experimental design was a $2 \times 2 \times$ 3 factorial. The first factor, which was manipulated between subjects, was the rate of item presentation: 2 or $6 \mathrm{sec}$ per item. The second factor was the experimental manipulation of rehearsal: primacy rehearse (PR) and control (C). The third factor was serial position: primacy, middle, or recency.

Seventy-two undergraduates at Osaka City University participated. None had served as subjects in Experiment 1. They were randomly assigned to the four groups, which had different combinations of presentation rate and rehearsal manipulation.

Materials and Apparatus. Materials and apparatus were the same as in Experiment 1.

Procedure. Except that a presentation rate condition was added and the RR condition removed, instructions and procedures were identical with those in Experiment 1. A postexperimental interview revealed that 2 subjects had expected the final recall test, so they were replaced

\section{Results and Discussion}

Immediate free recall. The immediate recall performance for the four groups is shown in Figure 4. Except for the main effect of rehearsal manipulation and the threeway interaction, all effects were significant [for presentation rate, $F(1,68)=44.67, p<.001$; for serial position, $F(2,136)=92.67, p<.001$; for presentation rate $\times$ rehearsal manipulation, $F(1,68)=4.10, p<.05$; for presentation rate $\times$ serial position, $F(2,136)=8.10$, $p<.001$; for rehearsal manipulation $\times$ serial position, 


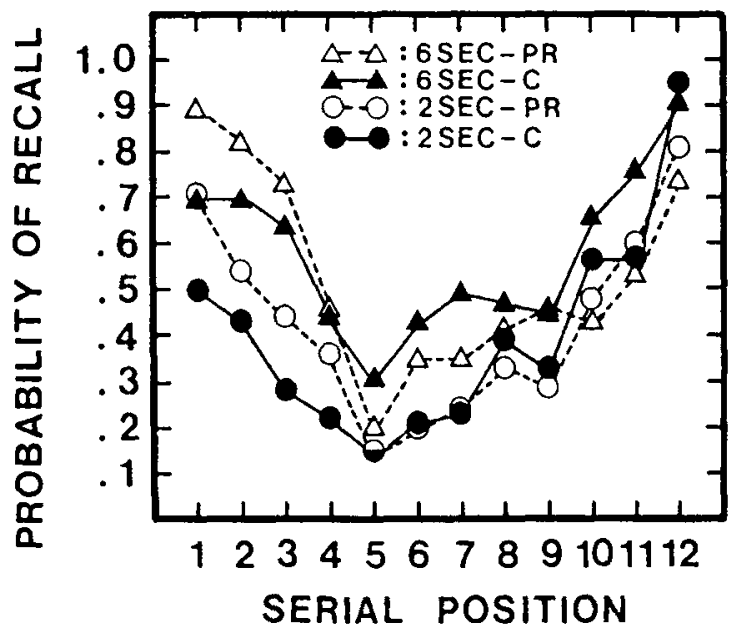

Figure 4. Serial position curves of immediate free recall for the four groups of combinations of presentation rate and rehearsal manipulation (Experiment 2).

$F(2,136)=15.35, p<.001]$. The significant main effect of presentation rate indicated better recall under the condition of 6-sec presentation rate for immediate recall. The interaction of presentation rate $\times$ rehearsal manipulation indicated that the difference between the PR and $C$ groups was greater at the higher presentation rate than at the lower rate. A tentative 2 (rehearsal manipulation) $\times 3$ (serial position) analysis of variance was subsequently carried out for each condition of presentation rate, although the three-way interaction was not significant. For the condition of the 2-sec rate, performance of the PR group was superior to that of the $\mathrm{C}$ group in the primacy region $[F(1,102)=12.35, p<.001]$ but not in the middle or recency positions. Under the 6-sec rate condition, the performance of the PR group was higher in the primacy positions $[F(1,102)=4.99, p<.05]$ but lower in the middle $[F(1,102)=4.16, p<.01]$ and recency positions $[F(1,102)=11.23, p<.001]$ than that of the $\mathrm{C}$ group.

Final free recall. Figure 5 shows the final recall performance. The main effects of presentation rate and serial position were significant $[F(1,68)=14.12, p<.001$; $F(2,136)=41.32, p<.001]$. There were significant interactions of rehearsal manipulation $\times$ serial position and of presentation rate $\times$ serial position $[F(2,136)=6.14$, $p<.01 ; F(2,136)=4.09, p<.01$, respectively]. Under the 2-sec rate condition, the PR group was superior to the $\mathrm{C}$ group in recall of items in the primacy positions $[F(1,102)=5.20, p<.05]$ and was equivalent to it in recall of items in the middle and recency positions. Under the 6-sec rate condition, there was no difference between the two groups regarding recall of items in the primacy positions, and the $\mathrm{C}$ group was relatively higher in recall of items in the middle and recency positions $[F(1,102)=4.67, p<.01 ; F(1,102)=3.84, .10>$ $p>.05]$.

The mean number of rehearsals. The mean number of rehearsals is shown in Figure 6. There were effects of presentation rate $[F(1,68)=159.95, p<.001]$, serial position $[F(2,136)=105.29, p<.001]$, presentation rate $\times$ serial position $[F(2,136)=20.28, p<.001]$, rehearsal manipulation $\times$ serial position $[F(2,136)=14.39$, $p<.001$ ], and presentation rate $\times$ rehearsal manipulation $\times$ serial position $[F(2,136)=3.89, p<.05]$. Under the condition of the $2-\mathrm{sec}$ rate, the PR group tended to be superior to the $\mathrm{C}$ group in recall of primacy items $[F(1,102)=3.32, .10>p>.05]$, but there was no difference in recall of middle and recency items by the two groups. Analogous results were obtained under the 6-sec rate condition [for primacy items, $F(1,102)=$ $19.61, p<.001$; for middle and recency items, both $F \mathrm{~s}$ $<1]$.

In order to clarify the effect of the number of rehearsals on primacy items, the occasions for subjects' rehearsal were extended in Experiment 2 by manipulating the rate of item presentation. Evidence confirming the view that rehearsal increases recall performance was seen in the following findings: (1) higher immediate and final recall under the slower presentation rate, especially in the primacy serial positions (the position $\times$ rate interaction); (2) an advantage of the PR group over the $C$ group in recall of

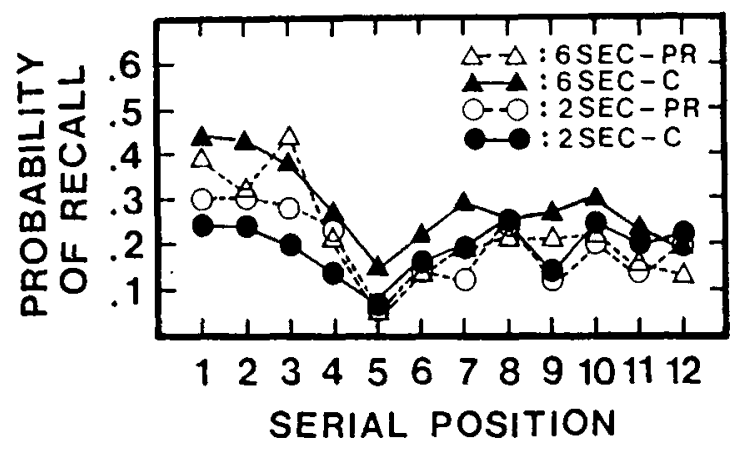

Figure 5. Serial position curves of final free recall for the four groups (Experiment 2).

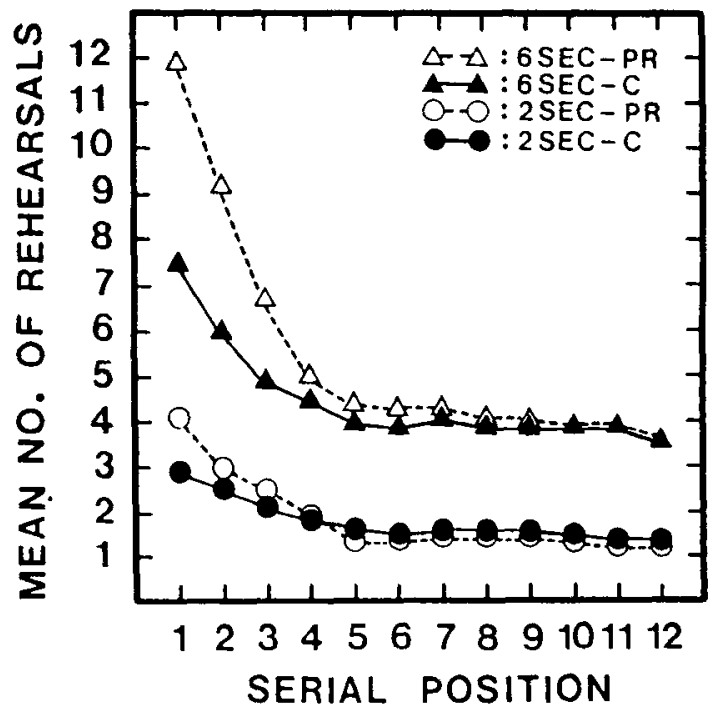

Figure 6. Mean number of overt rehearsals as a function of serial position (Experiment 2). 
items in the early serial positions in the final free recall test under the 2-sec rate condition; and (3) in the immediate and final tests, higher recall of the $\mathrm{C}$ group than the $P R$ group in recall of items in the later serial positions (the group $\times$ position interactions).

There was also, however, negative evidence for a facilitative effect of the number of rehearsals on long-term recall. Under the 6-sec rate, the increase in the number of rehearsals for primacy items was remarkable. Moreover, recall performance for primacy items was facilitated in the immediate test, but not in the final one. The difference between the number of rehearsals for primacy items for the $\mathrm{C}$ and $\mathrm{PR}$ groups seems to be related to immediate recall, but not to final recall. In general, the above-mentioned hypothesis that sufficient rehearsal time would induce the superiority of the PR group was not supported. It is evident that long-term recall is not necessarily regulated by the amount of rehearsal for primacy items.

\section{GENERAL DISCUSSION}

In the present study the relationship between long-term performance and the number of rehearsals was examined by means of an overt rehearsal procedure. Particular attention was paid to the relationship between the recall performance for primacy items and the number of rehearsals that they received. The results of Experiments 1 and 2 showed that for neither recency nor primacy items does the additional overt rehearsal reliably lead to enhancement effects on long-term recall performance.

It was confirmed by the comparison of the $C$ and $R R$ groups in Experiment 1 that maintenance rehearsal, which helps to maintain information of items in the short-term store but does not lead to good long-term retention, was executed for recency items. Furthermore, the overall pattern of the data suggested that even for primacy items, for which elaborative rehearsal would be expected, there is not a positive linear relationship between the number of rehearsals and the extent of organization or elaboration of materials. Thus it is difficult to explain these results in terms of a simple dichotomy of maintenance and elaborative rehearsal.

An interesting finding is that the lower the rate of list presentation is and the more frequently the primacy items are rehearsed, the less the additional rehearsal activity facilitates long-term recall. The mean differences in the number of rehearsals between the $P R$ and $C$ groups for primacy items under the 2-sec (Experiment 2), 4-sec (Experiment 1), and 6-sec (Experiment 2) rate conditions are $.52,1.28$, and 2.47 , respectively. On the contrary, the corresponding mean differences in the probability of final recall between them are $.07, .02$, and - -04 , respectively. Figure 7 presents the correlation between the final recall probability of list items and the number of rehearsals accorded to them. Roughly speaking, the gradients of regression lines can be considered as a measure of transfer ef- ficiency of rehearsal to long-term storage. The gradient for the $\mathrm{C}$ group is steeper as rate of list presentation is slower, whereas that for the PR group is more shallow, owing to the low recall probability of the emphasized primacy items that received more rehearsals. This indicates that the additional rehearsal activity is effective for long-term performance under the restricted condition of rehearsing owing to rapid presentation, and gradually becomes irrelevant as the opportunity for rehearsal increases. In fact, additional rehearsal of some items may interfere with others, as indicated by the $\mathrm{C}$ group's higher immediate and final recall of nonprimacy items.

This fact can be interpreted easily with reference to the time allowed for rehearsing, if it is assumed that a manipulation of the amount of rehearsal in the present experiments induces a concomitant change in the qualitative nature of the rehearsal. As shown in Figures 3 and 6, for the PR group (and also the RR group) of Experiment 1 and for the PR groups in both presentation rate conditions of Experiment 2, subjects rehearsed the emphasized items more than nonemphasized items, but they did so by increasing their rehearsal rate. The number of rehearsals of the nonemphasized items continued to be about the same as for control list items, so the additional rehearsals of the emphasized items did not come from reallocation. Rather, the emphasized items received more rehearsals in the allotted time, constituting increase in rehearsal rate. Thus, it is reasonable to assume that the qualitative nature of the rehearsal changed with the subject's rehearsal rate. Basically, rehearsal becomes less effective for long-term storage as the number of rehearsals increases.

As a final note, two points should be made concerning the present results. The first is the possibility that recall might have been affected by output-order strategy and output interference. If the subjects use a primacy-first strategy, the primacy items, receiving early output priority, should have an advantage for immediate recall, and they would be retroactively interfered with by later recalled items (Dalezman, 1976). Thus output priority may exert a positive effect on immediate recall and a negative effect on final recall. An attempt was made to perform an outputorder analysis on part of the results, by means of the measure of the Relative Index of Priority, RIP (Maskarinec \& Brown, 1974), in which the greater positive and negative scores show the earlier and later output priority, respectively. RIP scores of the $\mathrm{C}$ group in Experiment 1 for primacy, middle, and recency regions were -.16 , -.27 , and +.29 , respectively, whereas those of the PR group were $+.13,-.24$, and -.02 , respectively. Emphasizing some items in red seems to lead subjects to give those items early output priority in immediate recall. The superior immediate recall of the PR group to the $\mathrm{C}$ group may be affected by the subjects' primacy-first strategy, but no difference of final recall was observed between the two groups regarding the primacy items. This finding does not necessarily show that the primacy items were subject to output interference from later items, because 


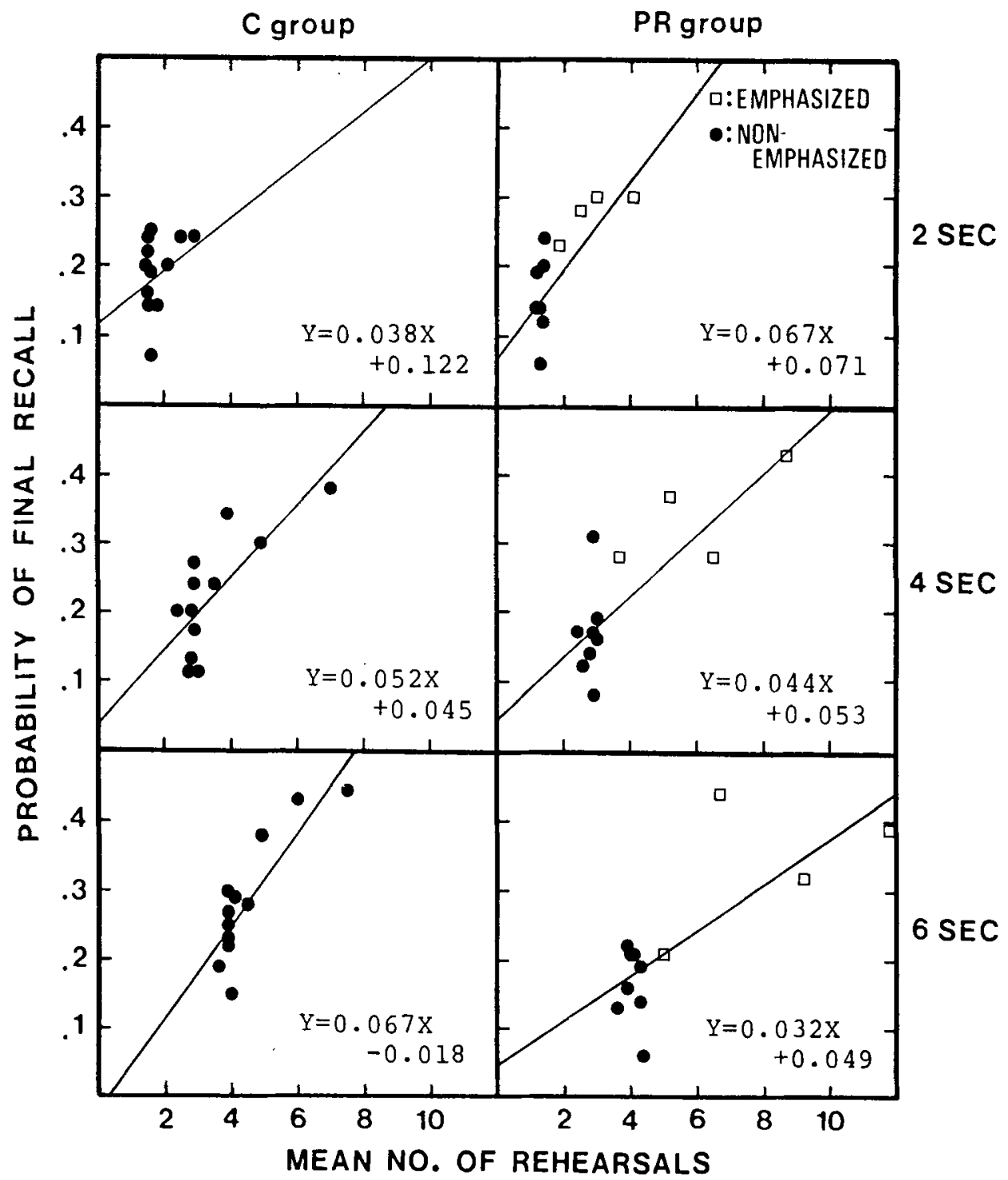

Figure 7. The correlation between the final recall probability of list items and the number of rehearsals accorded to them.

output interference should make the performance of the PR group lower than that of the $\mathrm{C}$ group regarding the primacy region in final recall.

The second point is that in the present experiments a correlational approach is ultimately adopted in order to examine the relationship between rehearsal and recall, as in Rundus's (1971) experiments. The direction of the relationship is uncertain; furthermore, "it is possible that subjects rehearse those items that they recall most readily and they would recall later in any case, rather than that rehearsal is the cause of recall' (Klatzky, 1980, pp. 113115). We cannot help acknowledging this limitation, unless a causal approach is used instead of this approach.

In conclusion, the main finding in the present study is that neither the primacy effect nor the recency effect is closely related to the number of times the word is rehearsed. In other words, the number of rehearsals on the beginning items of the list is demonstrated not to be a particularly good indicator of long-term performance, even in a situation where it was thought to provide a good one.

\section{REFERENCES}

Atkinson, R. C., \& Shiffrin, R. M. (1968). Human memory: A proposed system and its control processes. In K. W. Spence \& J. T. Spence (Eds.), The psychology of learning and motivation: Advances in research and theory (Vol. 2, pp. 89-195). New York: Academic Press.

Atkinson, R. C., \& Shiffrin, R. M. (1971). The control of short-term memory. Scientific American, 224, 82-90.

Craik, F. I. M. (1970). The fate of primary memory in free recall. Journal of Verbal Learning \& Verbal Behavior, 9, 143-148. 
Craik, F. I. M., \& LockHART, R. S. (1972). Levels of processing: A framework for memory research. Joumal of Verbal Learning \& Verbal Behavior, 11, 671-684.

Craik, F. I. M., \& Watkins, M. J. (1973). The role of rehearsal in short-term memory. Journal of Verbal Learning \& Verbal Behavior, 12, 599-607.

Dalezman, J. J. (1976). Effects of output order on immediate, delayed, and final recall performance. Journal of Experimental Psychology: Human Learning \& Memory, 2, 597-608.

KLATZKY, R. L. (1980). Human memony: Structures and processes (2nd ed.). San Francisco: W. H. Freeman.

Koyanagi, K., Ishikawa, S., Ohkubo, Y., \& IshiI, E. (1960). The familiarity values of Japanese three-letter nouns. Japanese Journal of Psychology, 30, 357-365. (In Japanese with English summary)
Maskarinec, A. S., \& Brown, S. C. (1974). Positive and negative recency effects in free recall learning. Joumal of Verbal Leaming \& Verbal Behavior, 13, 328-334.

Rundus, D. (1971). Analysis of rehearsal processes in free recall. Journal of Experimental Psychology, 89, 63-77.

Rundus, D., \& Atkinson, R. C. (1970). Rehearsal processes in free recall: A procedure for direct observation. Journal of Verbal Learning \& Verbal Behavior, 9, 99-105.

(Manuscript received March 4, 1986; revision accepted for publication July 8,1986 .) 